\title{
Albanon
}

Revistë kulturore

\section{Rruga për në Elbasan, Bernard Newman, 1936}

Vilma Tafani

Ky fragment përfshin kapitullin X të librit "Dera e pasme e Shqipërisë", shkruar nga Bernard Njuman, më 1936. I gjithë kapitulli, që titullohet "Rruga për në Elbasan”, është në vetën e parë. Autori përshkruan udhëtimin e tij dhe vizitat në Elbasan në formën e përshtypjeve dhe mbresave të tij për Elbasanin dhe elbasanasit. Bernard Njuman njihet si njeriu që shëtiti nëpër Shqipëri kryesisht me biçikletë.

Hyrja në Shqipëri do të bëhej nga Shën Naumi përmes një letre zyrtare, një letër, notë verbale, e cila do t’i lejonte kalimin e kufirit atij dhe Xhorxhit (biçikletës) pa vështirësi. Nota zyrtare që i kishte dhënë ministri jugosllav në Londër, nuk e kishte realizuar qëllimin kur hyri në Jugosllavi. Atij i dukej e kotë të shpresonte se letra e ministrit shqiptar do të kishte ndonjë rezultat më të mirë.

Por, ndërsa ai dhe biçikleta (autori përdor gjithmonë numrin shumës duke e quajtur biçikletën si bashkëudhëtare), po i afroheshin postës shqiptare, menjëherë doli që andej një oficer dhe iu drejtua atyre në anglisht. Autori u çudit kur dëgjoi në distancë të flitej në anglisht.

“- A jeni ju zoti Njuman?

Autori u përgjigj: - Po, unë jam.

- Mirë se vjen në Shqipëri. - foli ai me zë të lartë."

Ndërkohë Bernard ishte afruar aq shumë sa ata të dy shtrënguan duart fort. Ai nuk ishte mësuar me pritje zyrtare dhe gjithçka po i dukej si diçka misterioze, derisa oficeri i shpjegoi se si ishte puna. Me sa dukej, ministri 
shqiptar në Londër i kishte çuar lajm Tiranës për të lajmëruar ardhjen e tij nga Shën Naumi. Natyrisht ai nuk e kishte idenë se kur do të arrinte në Shqipëri Bernard Njuman, por menjëherë qeveria shqiptare, sapo kishte marrë letrën e tij kishte dërguar një roje kufiri që fliste anglisht dhe e kishte vendosur në pikën kufitare të Shën Naumit, që t’ $i$ jepte një mirëseardhje të veçantë dhe zyrtare mikut nga Anglia. Ky episod tregon edhe një herë mikpritjen e shqiptarëve. Ata shqetësohen, tregojnë interes, kujdesen dhe marrin masat e nevojshme, që ta bëjnë vizitën e një miku sa më të këndshme.

Autori kujton se kurrë në jetën e tij nuk kishte kaluar kufirin e një shteti kaq lehtë. Kur u bë gati që të nisej për rrugë, vuri re se oficeri, që fliste anglisht po përgatitej që ta shoqëronte. Natyrisht që Bernard e kuptonte që oficeri po mendonte vetëm për të mirën e vizitorit nga Anglia; donte ta shoqëronte atë të paktën deri në Pogradec, si përkthyes, por ai e falënderoi atë sinqerisht dhe iu lut ta lejonte të niste i vetëm udhëtimin e tij nëpër Shqipëri.

Elbasani, pikësynimi i shpejtë i Bernardit, ishte vetëm nja njëqind kilometra larg dhe atij i kishin mbetur vetëm 12 orë ditë. Kështu që ai vendosi të nisej menjëherë. Brenda një ore që ishte larguar nga Shën Naumi, ai ishte gati të fillonte itinerarin e tij të ri. Natyrisht rruga nuk ishte aspak e mirë. "Nuk mund ta saktësoje nëse ishte rrugë dhish apo rrugë e klasit të tretë - kujton autori. - Ngadonjëherë ishte e gjerë aq sa të kalonte një karrocë, por mund të them me bindje të plotë që ajo asnjëherë nuk ishte përdorur nga karrocat, por vetëm nga gomerët". Në dhjetë miljet e para, autori hipi në biçikletë vetëm nja 100 metra, pjesën tjetër e bëri të gjithë në këmbë, duke tërhequr biçikletën. Nuk kishte arsye pse ai të mundohej t’ i jepte biçikletës duke iu ngjitur maleve të thepisur dhe me djersën që i kullonte çurk.

Kur arriti në Pogradec e kishte marrë shumë uria dhe në hanin më të parë gjeti ushqimin gati. Autori i librit, kishte vështirësi edhe me paratë, me monedhat shqiptare. Ai e dinte se monedha standarde ishte "leku". Nga banka e tij në Angli ai kishte marrë disa kartëmonedha të vjetra, të zhubrosura e të pista që shkruanin: kartëmonedha "5-lekëshe". Nëpunësi i bankës në Angli ishte intriguar nga pamja e këtyre kartëmonedhave të çuditshme. Ai kishte bërë llogarinë dhe i kishte thënë autorit se 1 lek ishte i barasvlefshëm me 1 shilingë e 3 pencë. Kështu që kur pronari i hanit i tha atij se dreka kushtonte 2 lekë, ai u shqetësua shumë. "Nëse një drekë kaq e thjeshtë do të kushtonte gjysmë korone - mendoi autori - atëherë qëndrimi i tij në Shqipëri do të ishte shumë më i shtrenjtë nga ç’e kishte parashikuar." 


\section{Albanon}

\section{Revistë kulturore}

Megjithatë ai i dha pronarit të hanit një kartëmonedhë 5-lekëshe dhe ai dërgoi një çunak ta thyente atë diku. Më pas, për çudinë e tij, ai mori si kusur 23 monedha metalike. Fatmirësisht në han ndodhej një njeri që njihte gjuhët, i cili ia sqaroi atij situatën. Kartëmonedha që kishte autori nuk ishte e vlefshme 5 lekë, por 5 franga floriri. $\mathrm{Një} \mathrm{frangë} \mathrm{floriri} \mathrm{ishte} \mathrm{e} \mathrm{vlefshme} 5$ lekë; kështu që ai e kuptoi që 1 lek i tij ishte i barazvlefshëm me 3 lekë sipas monedhës në përdorim. Tashmë, autori u lehtësua nga tmerri që e kishte pushtuar dhe mendoi se kjo drekë ia vlente të ishte 6 pencë, madje edhe ca më shumë.

Rruga drejt veriut ishte deri diku e frikshme dhe shumë e keqe.

Megjithatë ai vazhdoi rrugën, duke menduar se ishte "punë për burra" të ecje nëpër rrugë të këqija e të frikshme. E tatëpjeta herë-herë ishte shumë e ashpër, e pjerrët, por autorin nuk e shqetësonte aq shumë pjerrësia, sesa rruga me gurë të hedhur andej-këndej dhe që ishin shumë të rrezikshëm.

Zbritja nga Qafë Thana ishte akoma më shumë acaruese dhe më e lodhshme se ngjitja, sepse rruga ishte aq e keqe saqë ishte absurde të mendoje të ngisje biçikletën. Në vendet ku rruga nuk ishte e mbuluar me gurët e hedhur, ajo vazhdonte thjesht në faqet e shkëmbit, të cilat ishin shumë të thepisura dhe me shumë të çara. Autori në ato çaste ishte shumë i dëshpëruar dhe kujton: "Madje as në Bullgari, as në Rusi, as në Poloni nuk më kujtohet të kem pasur një ditë udhëtimi kaq të pashpresë, kaq demoralizuese.".

Vonë në mbrëmje autori mbërriti në luginën poshtë Qafë Thanës. Atje ai vuri re se kjo luginë ishte shumë pak e populluar. Megjithatë ai u lumturua kur pa grupe fshatarësh që ende po punonin në fushat përqark. Fshatarët u çuditën kur panë të huajin dhe menjëherë i lanë drapinjtë, nxituan në drejtim të rrugës dhe shtrënguan duart ngrohtësisht me të. Ai u mrekullua nga kjo gjë dhe shkruan: "Nëse ky do të ishte një model i mirësjelljes shqiptare, ishte diçka e mrekullueshme, me shumë fryt. Padyshim ata po më ofronin mua urimet dhe përgëzimet e tyre më të përzemërta, që unë kisha kapërxyer malin (Qafé Thanën) me biçikletë dhe unë e ndjeva që e meritoja respektin e tyre."

Biseda me ta natyrisht ishte e kufizuar, por kur autori përmendi fjalën Elbasan, ata ngritën duart dhe bënin me shenja, që autori i interpretoi sikur ata ishin dakord që ai të nisej për udhëtim. Miqësia e tyre ishte shumë e dukshme, madje disa prej tyre e shoqëruan atë, duke ecur rreth një milje, derisa udhëtari takoi një grup tjetër fshatarësh. Më vonë autori e kuptoi se kjo përcjellje ishte një relike e mrekullueshme e mikpritjes së hershme në Shqipëri. 
Ai e dinte se 20 vjet më parë do të ishte pasiguri e madhe për këdo që do të udhëtonte i vetëm nëpër këto anë, prandaj ishte krijuar një farë sistemi i tillë eskorte, apo shoqërimi i miqve deri në sinoret e caktuara. Kjo gjë tashmë ishte bërë traditë mes shqiptarëve. Burrat e një familjeje apo të një fisi, e shoqëronin të huajin apo mikun deri në kufirin e tokave të tyre, që të ishin të sigurtë mos i ndodhte gjë mikut në pronat e tyre.

E ai vazhdonte të ecte e të ecte. Ethet sikur i kishin kaluar, por kur arriti në Xhyrë ishte plotësisht i dërrmuar. Hani që gjeti atje nuk iu duk aspak premtues, por atij i kishte "ardhur atje ku s'mbante më litari", i kishte sosur durimi dhe kërkoi të flinte menjëherë, pavarësisht se si ishte dhoma.

Dita tjetër ishte njësoj si e para, përsëritje e së njëjtës histori, veçse ditën e dytë ai ndoqi kryesisht rrjedhën e lumit Shkumbin. Lugina e lumit ishte shumë e këndshme dhe në disa raste zbuloheshin bukuri të rralla, mahnitëse. Dhe, sikur rruga të ishte diçka më e mirë, ai do ta kish shijuar akoma më shumë këtë bukuri.

Por, sa më shumë i afrohej Elbasanit, aq më shumë rruga përmirësohej dhe ai mundi të bëjë një pjesë të mirë të rrugës me biçikletë. Kasollet dhe fshatrat ishin shumë të rralla dhe këto me një distancë jo pak, por rreth 10 milje. Por kjo nuk ishte diçka për $t$ ' $u$ çuditur, pasi autori e vuri re me lehtësi se ky rajon kishte burime shumë të pakta jetese, pasi vetëm lugina kultivohej, ndërsa fushat e pakta me misër "rakitik", shpejt humbisnin në gëmushat e shpateve të zhveshura të maleve përreth. Rugës autori vuri re dy ura turke, të cilat i bënë shumë përshtypje, "bukurinë e të cilave ai kishte kohë që ëndërronte t` $i$ shihte”. Njëra nga to ishte pothuajse e rrënuar fare, por pavarësisht nga kjo, ajo ruante ende karakterin e saj dhe i shkonte mjedisit përreth.

Kështu, i dërrmuar plotësisht, Bernard Njuman, arriti në Elbasan, për të cilin shkruan se"është një nga qytetet më interesante të Shqipërisë, dhe pse jo edhe të Ballkanit".

Para se të nisej, atij i kishin rekomanduar të shkonte tek hotel Adriatiku. Një han anglez do të "shtrembëronte turinjtë", kur të shihte një vend të tillë që mëtonte të kishte një emër kaq pretendues, por të paktën ishte i pastër, të vetmen gjë që autori dëshironte ta kishte pas gjithë atyre peripecive që kishte kaluar. Vështirësitë e gjuhës u zhdukën menjëherë, brenda pesë minutave. Ndërkohë që ai po mundohej të vendoste diku biçikletën, një djalosh që doli nga dera, iu afrua dhe iu drejtua atij me një anglishte të mrekullueshme, pasi "ai kishte mbaruar Kolegjin Amerikan në Durrës dhe për nga profesioni ishte specialist hortikulture; merrej kryesisht me kopshtari." 


\section{Albanon}

\section{Revistë kulturore}

Me sa kuptoi udhëtari i huaj, ai nuk dukej se kishte shumë punë dhe e vuri veten dhe ndihmësin e tij, plotësisht në dispozicion të mikut nga larg.

Menjëherë autori filloi të eksplorojë Elbasanin. Ai e dinte se dy breza më parë Elbasani ishte pothuaj një qytet i harruar dhe i ndaluari; një qytet mysliman, shumë fanatik dhe të krishterët nuk mirëpriteshin atje. Banditët e shumtë që ishin në këtë rajon e bënin hyrjen në qytet pothuajse të pamundur.

Që të hyje në Elbasan, ose të kalojë përmes tij, ishte e domosdoshme të merrje me qera një eskortë të kavalerisë turke që të të shoqëronin gjatë udhëtimit. Por edhe kjo nuk të siguronte udhëtim të sigurt. Kishte shumë të ngjarë që të afërmit e tu do të merrnin një pako me një nga veshët e tu të prerë, ku do t’u kërkohej një shumë e majme, si kompesim për të të liruar ty, ose ndonjë gjë tjetër, një Zot e di se çfarë mund t'u shkonte nëpër mend atyre. Por, edhe nëse ndodhte që banditët shqiptarë nuk do të të plaçkisnin ty, do të ishte eskorta turke, që do të kujdesej për këtë gjë, që ty mos të të ngelte merak se nuk e shijove plaçkitjen.

"Ndërsa tani - kujton autori (është viti 1935, shënim i V.T.), - çdo njeri mund të hyjë në Elbasan, madje për më tepër edhe gratë.”

Elbasani, në atë kohë, ishte një qytet me përmasa të konsiderueshme. Aty kishte një pazar, "në të cilin qëndronin të ngjeshur, njëri pas tjetrit 1000 dyqane”, një pazar që ishte shumë më primitiv dhe më pak i sofistikuar sesa pazari i Sarajevës, që autori e kishte parë para ca kohësh. Treçereku i popullsisë së Elbasanit ishte në atë kohë myslimane. Dhe kaq i fortë ishte ndikimi mysliman, sidomos në veshjet e grave, saqë edhe gratë e krishtera shpesh mbulonin fytyrat e tyre me perçe.

Pjesa qendrore e qytetit, duke përfshirë edhe pazarin, ishte e rrethuar me mure të lartë e të fortë, fragmente të të cilëve dhe porta piktoreske e hyrjes ende mbijetonin. Autori shkruan: "Ura e vjetër mbi lumin Shkumbin (është fjala për një urë të rrugës Egnatia, shënim i V.T.), e cila kishte qenë krenaria arkitekturale e Elbasanit, tashmë është shkatërruar dhe është zëvendësuar me një “monstruozitet" modern, por që praktikisht, është më i vlefshëm sesa rrënojat e lashtësisë."

Shumë intrigues i dukej autorit një vend takimi i hapur muhamedan, që ishte në formën e një platformë të ngritur dhe tërësisht i zbuluar nga jashtë. Ky vend përdorej në ditë të shënuara fetare, kur ishte e pamundur që të gjithë njerëzit të hynin brenda në xhami. Shumë pranë këtij vendi ishte një kishë ortodokse, me harqe. Kjo ndërtesë të impononte respekt me pamjen e saj dinjitoze. 
Afër lumit, ndodhej një tjetër xhami shumë e vjetër, si "e mbijetuara, dëshmitarja e vetme e një Elbasani shumë më të vjetër”. Ajo dëshmonte jetëgjatësinë e një Elbasani shumë më të lashtë sesa dukej në pamje.

Përveç pazarit dhe qendrës së qytetit, rrugët në periferi të Elbasanit ishin çuditërisht monotone, sepse mure me gurë të mëdhenj fshihnin pas tyre kopshtet me pemë, aq të përmendur dhe ishte e pamundur që syri i kalimtarit në rrugë, të shihte çfarë fshihej prapa tyre, por nga ana tjetër, ato shërbenin për të ndaluar të huajt të hidhnin vështrimin drejt grave të pambuluara. Megjithatë, me ndihmën e shokut të tij, specialistit të hortikulturës, i cili ishte edhe vetë mysliman, ata nuk e patën edhe aq të vështirë të ndërfuteshin në "misterin e kësaj barriere mbrojtëse".

Specialisti i hortikulturës kishte ardhur në Elbasan me një mision të veçantë. Siç dihet, qyteti i Elbasanit ishte i famshëm për pemët e portokalleve dhe çdo shtëpi, brenda këtyre kopshteve të rrethuara me mure, kishte "gjysmë dyzine" ose më shumë pemë të tilla.

Autori u befasua kur dëgjoi se çdo rrënjë portokalli prodhonte mesatarisht 10.000 kokrra portokalli. Në ato vite, me sa dukej, pemët e portokalleve në Elbasan po dëmtoheshin dhe kishin rënë pre e një buburreci të vogël e të zi, që po bënte kërdinë. Ishte kjo arsyeja, që eksperti i hortikulturës, miku i autorit, ishte dërguar në këtë zonë për hetim. Ai e kishte identifikuar buburrecin dhe kishte mundur të gjente edhe ilaçin me të cilin mund të luftohej ai.

"Një ngjarje shpresëdhënëse, ndriçuese, - kujton autori - ne mundëm të hynim në një nga kopshtet e shtëpive elbasanase dhe pasi pritëm për një kohë relativisht të gjatë te dera, sa të mbuloheshin gratë e shtëpisë, porta u hap dhe ne u futëm brenda."

Ndërsa specialisti i hortikulturës merrej me insektet, autori mundohej të bënte muhabet me të zotin e shtëpisë. Disa metra më tutje qëndronte gruaja e tij, e mbuluar rëndë që mos të depërtonte vështrimi i dyshimtë i të huajit. Megjithatë, ndërkohë që ata bisedonin, ajo filloi të ushqente foshnjën e saj dhe shumë natyrshëm dhe pa i ardhur zor fare, zbuloi gjirin e saj të bardhë përpara atij vështrimi të dyshimtë.

Në Elbasan Bernard Njuman takoi edhe njerëz të tjerë, që dinin të flisnin anglisht. Eksperti i hortikulturës i tha se atje, ato kohë, banonte edhe një grua londineze. Kështu që së bashku me specialistin e hortikulturës autori shkoi në shtëpinë e një dentisti. Ai fliste një anglishte të rrjedhshme. Dentisti nga Armenia, kishte jetuar për ca kohë në Londër dhe atje ishte martuar me një 


\section{Albanon}

\section{Revistë kulturore}

vajzë nga Hemstëd (Hamstead), edhe ajo nga Armenia, por me nënshtetësi britanike.

Një nga muret e apartamentit të tyre kishte një të çarë, rrjedhojë e një tërmeti që kishte rënë kohët e fundit. Shqipëria shtrihet në brezin evropian të tërmeteve, por për fat të mirë, tërmetet nuk kanë qenë aq të fortë dhe “janë sjellë mirë" me Shqipërinë, duke dhënë paralajmërime të vogla dhe tronditje të lehta para se të binte tërmeti i vërtetë.

Në Elbasan autori takoi edhe një njeri tjetër që fliste anglisht, fama e të cilit kishte kaluar çdo kufi. Ajo ishte e mirënjohura Margaret Hasllëk (Hasluck), e cila është ndoshta një nga personalitetet me famë botërore për njohjen që ka mbi gjuhën shqipe dhe veçanërisht mbi folklorin shqiptar. Ajo kishte shkruar një gramatikë standarde të gjuhës shqipe, kishte mbledhur një numër të madh tregimesh folklorike me rëndësi të veçantë.

Në kohën kur autori po vizitonte Elbasanin, Margaret Hasllëk kishte ardhur përsëri në Shqipëri dhe ishte vendosur në Elbasan për pesë vjet të tjera për të përfunduar një koleksion tjetër të serive të saj folklorike. Ajo ishte një personalitet i padiskutueshëm, e cila të impononte respekt dhe kishte një ndikim të madh në Elbasan. Autori shkruan për të: "Nuk e di nëse këshilli i qytetit konsultohet ndonjëherë me të para se të marrë vendime të ndryshme, por në qoftë se nuk e bën një gjë të tillë, di të them që ky këshill nuk ka vepruar me zgjuarsi."

"Është disi e çuditshme, - vazhdon autori - por dy autoritetet më në zë britanike dhe më të suksesshme në Shqipëri, kanë qenë gra. Tridhjetë vjet më parë Edit Durhami ishte pothuajse e para e huaj që mund të fliste dhe të shkruante në mënyrë origjinale për Shqipërinë dhe popullin e saj, nga burime të eksploruara vetë. Tani "manteli" i saj ka rënë mbi Margaret Hasllëkun, - vazhdon autori - të dyja këto janë gra me personalitet të fortë dhe me kulturë të gjerë dhe asnjëra nga ato nuk e ka zhgënjyer Britaninë."

Autorit i pëlqeu shumë mënyra se si Margaret Hasllëku, u fliste tre miqve të tij të rinj, që e shoqëronin. Të tre ishin ndër të paktit të shkolluar në Shqipëri.

"Mbajeni vath në vesh - u thoshte ajo atyre, pas një leksioni të vogël - e ardhmja e Shqipërisë varet nga ju. Shqipëria tani është e mbushur me korrupsion dhe s’ka si të jetë ndryshe. Njerëzit që janë në pushtet tani, kanë marrë edukatë dhe arsim sipas traditës turke. Askush nuk pret që ata të heqin dorë nga përdorimi i mënyrave tradicionale. Por shumë shpejt brezit të tyre do t’ $i$ kalojë koha dhe ju do t` $i$ zini vendin. Çfarë do të bëni ju atëherë? Nëse ju do të vazhdoni të njëjtën 
rrugë siç vepruan ata, atëherë, nuk do të ketë vend në hartën e Evropës për Shqipërinë. Nëse ju do të mundoheni të prezantoni në jetën shoqërore shqiptare kodin moral që keni mësuar në shkollat amerikane, angleze apo franceze, atëherë e ardhmja e Shqipërisë do të jetë e shndritshme."

Harroni për një çast që këto fjalë janë thënë plot 70 vjet më parë. Ato janë po aq aktuale edhe tani, madje mund të themi pa e tepruar se ato i përshtaten më së miri periudhës që po kalojmë ne sot. Sikur ta dinte Margaret Hasllëku që fjalët e saj do të kishin kaq jetëgjatësi ndoshta do të mërzitej. Ajo nuk do t’ia uronte shqiptarëve këtë endje ndër vite. E si ka mundësi që historia e përsërit vetveten në një kohë kaq të shkurtër dhe fjalët korrupsion qeveritar të rikthehen pas kaq vitesh përsëri, po me atë forcë, madje edhe ca më fort?!

Më tej Bernard Njuman vazhdon me këshillat e saj: "Mbani mend gjithmonë se detyra e Shqipërisë është shumë e vështirë, sidomos kur ajo mundohet të bindë kombet e tjera evropiane se ajo duhet të trajtohet në pozita të barabarta me to. Ju jeni myslimanë, shumica e shqiptarëve janë myslimanë dhe Evropa e shikon myslimanizmin si diçka që i përket tërësisht Lindjes, Azisë dhe Afrikës dhe aspak Evropës. Ju duhet ta luftoni e ta mposhtni këtë paragjykim, vendi juaj është në Evropë... Ju mund të bëni ç'të doni me bindjet tuaja fetare, por duhet të bëni kujdes që idetë tuaja myslimane të mos sundojnë politikën. Unë mendoj se ju nuk jeni myslimanë të ngurtë, madje nga kjo anë ju nuk jeni të zjarrtë për çdo lloj çështje fetare... E di që është e pamundur, por unë do të kisha shumë dëshirë që Shqipëria të përfshihej nga një ringjallje e fortë fetare që unë do të pëlqeja të ishte e tipit jo konformist... Ju shqiptarët, keni pothuajse gjithçka, ju keni shëndetin, forcën, inteligjencën dhe kurajën. Ajo për të cilën keni nevojë tani për tani është një kurajo morale dhe vetëm kur ta keni edhe këtë, ju do të bëheni një komb i madh, ndonëse jeni një komb i vogël për nga madhësia...”. Vazhdimisht ajo përsëriste: "Mbajeni mend mirë, gjithçka varet vetëm nga ju, brezi i ardhshëm. Shumë vendeve do t’u pëlqente ta gllabëronin Shqipërinë. Ato kanë shumë pretekse për ta bërë këtë gjë, në këto kohë. Duhet patjetër që ju në këto çaste të përpiqeni ti $i$ zhdukni këto pretendime..."

Miqtë e autorit u prekën shumë, pasi në atë kohë, Margaret Hasllëk ishte një legjendë në gjithë Shqipërinë. Ajo ishte një grua, që mundi të jetonte vetëm në një vend të huaj dhe të egër, në një vend ku gratë mbaheshin si seksi më i dobët dhe, të jetoje në një vend të tillë dhe në një kohë të tillë ishte në të vërtetë e jashtëzakonshme.

Më tej autori takoi një anëtar të parlamentit nga Elbasani. Ai e priti mikun nga Anglia më shumë dashamirësi dhe mirësjellje dhe, kur mori vesh se autori 


\section{Albanon}

\section{Revistë kulturore}

shkruante libra dhe mbante leksione, i kushtoi atij një orë plot nga koha e tij e çmuar dhe gjatë gjithë bisedës mundohej ta bindte autorin se Shqipëria ishte një vend i qetë dhe paqësor dhe autori, duke u nisur nga përvoja e atyre dy ditëve në Shqipëri, mendoi se ajo që thoshte deputeti ishte e vërtetë dhe pse, ndërkohë që deputeti fliste, roja e tij vetjake i armatosur, qëndronte vazhdimisht shumë pranë tij. Ai e shikonte mikun e huaj me shumë dyshim.

Pas takimit me deputetin, miqtë e autorit e pyetën atë nëse ai ishte i interesuar të vizitonte shkollën e mesme të vajzave në qytet. Kur ai shkoi atje, ai u befasua nga një ekspozitë e mrekullueshme me punë artistike të vajzave. Atij i pëlqyen veçanërisht qëndisjet që ishin bërë nga vajzat e shkollës. Autori mendonte se modelet nuk ishin plotësisht vendase, por dyshonte se ato kishin ndikim grek. Të tilla modele ai nuk i kishte parë në Shqipërinë e Veriut, ato nuk kishin asgjë të përbashkët me ato të veriut, prandaj autori mendonte se ato ishin të huazuara. Për këtë gjë shkruan: "Në jug, ku malet janë më të ulëta dhe rrugëkalimet janë më të mundshme, vendi natyrshëm është më $i$ hapur për të lejuar depërtimin e kulturës greke në thellësi..."

Pavarësisht nga kjo, ai e vlerësoi shumë ekspozitën dhe i mbetën në mendje për një kohë të gjatë sytë e mësueseve, që shkëlqenin nga gëzimi dhe krenaria, kur ai u tha se nxënëset e tyre kishin bërë një punë aq të mrekullueshme sa do të ishte e pabesueshme dhe e paarritshme për vajzat angleze të së njëjtës moshë.

Dy lloj profesionesh i tërhoqën vëmendjen më shumë autorit në Elbasan. I pari ishte shkrimi i letrave në publik, një profesion shumë i kërkuar në Elbasan, që kërkonte mjeshtëri të lartë, pasi jo më shumë se $1 \%$ e të rriturve mund të lexonin e të shkruanin. Një burrë i vjetër, i thatë dhe plot me rrudha, i cili dukej sikur mbante githë hallet e Elbasanit, (natyrisht ai mbante gjithë sekretet e tij), ecte rrugëve të qytetit, i kërrusur, nën çadrën e tij të stërmadhe. Ai merrte dy pencë (më pak se dy lekë) për të shkruar një letër dhe gjysmë peni për të lexuar një letër. Publiciteti i këtij profesioni ishte i çuditshëm. Autori tregon grimca të procedurave të shkrimit të letrave: "Me një gjysmë duzinë miqsh vendas (5-6 persona) unë po ndiqja një çast, kur një djalosh po i diktonte shkruesit të letrave, një letër të gjatë dhe po mundohej t'i shfaqte vajzës që ai kishte një dashuri të zjarrtë për të... Më vonë erdhi një vajzë me një letër në dorë dhe $i$ kërkoi atij t'ia lexonte atë. Nga vështrimi i syve të saj, dukej qartë se ia vlente të harxhoje gjysmë peni për ta lexuar atë letër..."

"Elbasani - shkruan autori në kujtimet e tij - është një përzierje e çuditshme e së lashtës dhe të së vjetrës me të renë e modernen. Nëpër rrugët e pazarit të tij 
të vjetër e të pandryshuar syri të sheh edhe shtylla për telat elektrike...” Një ditë autori pa një burrë që ishte mbështetur pas njërës prej këtyre emblemave të modernitetit shqiptar. Ai mbante një thes në kurriz dhe nga thesi pikonte ujë. Autori kujton: "E pyeta dhe mbeta gojëhapur. Elbasani është qytet shumë $i$ nxehtë, por është i rrethuar nga male të lartë të mbuluar me borë. Në këtë qytet, gjatë verës, ka kërkesa të mëdha për akull dhe ky burrë ngjitej 6000 këmbë (rreth $1800 \mathrm{~m}$ ) çdo mëngjes, ku ishin fushat me borë, e mbushte thesin e tij me akull natyral dhe zbriste përsëri. Ai më ofroi të ma shiste të gjithë thesin për 9 pens (3 lekë). Dymbëdhjetë mijë këmbë (-3600 m) ecje, ngjitje e zbritje për 3 lekë!!!! Epabesueshme!!!?

Një ditë tjetër, ditë pazari, fshatarët zbrisnin grupe-grupe nga fshatrat përreth me kafshët dhe sendet që do të shisnin. Disa ishin me pamje burrërore, mbi $1 \mathrm{~m}$ e $80 \mathrm{~cm}$ të gjatë, shpatullgjerë dhe me trup atleti. Ata zbrisnin nga malet dhe luginat me shpinën të ngarkuar me mallrat që do të shisnin, duke i konsideruar 30 miljet $(-45 \mathrm{~km})$ si një sport të mirë për muskujt e tyre. "Prandaj nuk çuditesha - shkruan autori - kur turqit i mbanin shqiptarët si lëndë e parë, e klasit të parë për ushtrinë e tyre, pasi fiziku i gegëve nuk e ka shokun në Evropë, s'ka të dytë... Megjithatë, edhe ata e kanë një pikë të dobët, 'thembrën e Akilit'... Si shumë popuj të tjerë të Ballkanit, shqiptarët janë shumë supersticiozë dhe e kanë frikë errësirën. Këtë e vura re qü në ditët e para të qëndrimit tim në Elbasan..."

Autori e konsideron Elbasanin si vendtakimin e dy fiseve, nëse mund t’ $\mathrm{i}$ quajmë kështu, gegët dhe toskët. Ai shkruan: "Në jug të lumit Shkumbin banojnë toskët dhe në veri të tij gegët. Ata flasin dialekte të ndryshme të së njëjtës gjuhë...” Autorit i duken më interesantë gegët, pasi toskët për shkak të lehtësisë së komunikimit në luginat e kalueshme kanë qenë gjithmonë më pranë dhe më të ndjeshëm ndaj ndikimeve të huaja, sidomos të grekëve. Kultura e tyre është në nivel më të lartë sesa ajo e gegëve, por fiziku dhe forca e tyre mashkullore nuk janë aq të dukshme sa te gegët. Gegët janë më pranë shqiptarëve primitivë, luftëtarëve të maleve, malësorëve trima, por kaçakë.

Autori pjesën më të madhe të udhëtimit të tij e kaloi nëpër territoret e gegëve dhe për këtë nuk u pendua kurrë. 